\title{
Peyer's patch is the essential site in initiating murine acute and lethal graft-versus- host reaction
}

Masako Murai, Hiroyuki Yoneyama, Taichi Ezaki, Makoto Suematsu, Yuya Terashima, Akihisa Harada, Hiromasa Hamada, Hitoshi Asakura, Hiromichi Ishikawa and Kouji Matsushima

Nature Immunology 4, 154-160 (2003).



\section{6d}

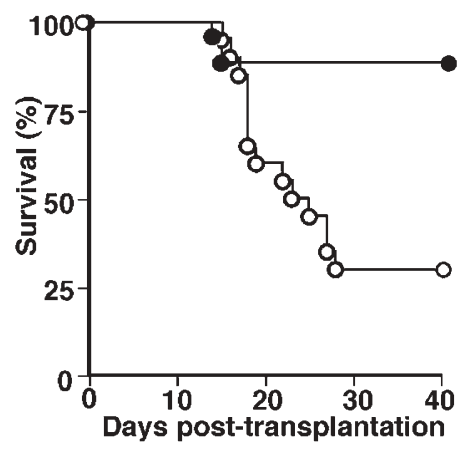

$6 e$

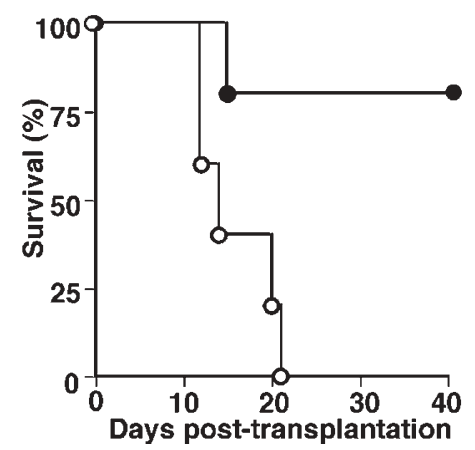

